\section{Case based measles surveillance performance in 2010, littoral region of Cameroon}

\author{
Gerald Etapelong Sume, ${ }^{1}$ \\ Marie Kobela, ${ }^{2}$ Dieula Delissaint, \\ Ditu Kazambu, ${ }^{1}$ Irène Emah ${ }^{2}$ \\ ${ }^{1}$ Central African Field Epidemiology \\ and Laboratory Training Programme; \\ ${ }^{2}$ The Central Technical Group for the \\ Expanded Programme on Immunization, \\ Cameroon
}

\section{Abstract}

The Littoral region of Cameroon met most of its routine immunization and surveillance objectives in 2010 but has not reiterated such a performance since then. We describe the casebased measles surveillance performance of 2010 by person, place, time and determine measles surveillance system delays. Descriptive statistics were performed using Epi Info 3.5.3. There were 130 suspected measles cases investigated by $17(89.5 \%)$ health districts, $83(64 \%)$ males and $99(76 \%) \leq 5$ years. At least 4 cases were investigated per month with a peak of 23 cases in June. About 67 (51.5\%) patients visited a hospital more than $48 \mathrm{~h}$ after disease onset, $34(26.2 \%)$ health facilities informed the district service late after receiving a suspected case and 65 (50\%) samples got to the reference laboratory more than $24 \mathrm{~h}$ after reception by the specimen collection centre. More than 2 discarded measles $/ 100,000$ population were investigated but with health facilities, specimen collection centre and patients' ability to seek healthcare delays. All specimens got to the reference laboratory within $72 \mathrm{~h}$. Patients' health seeking behavior need to be improved and personnel involved in surveillance sensitized on timeliness.

\section{Introduction}

Measles is an infectious viral disease affecting mostly children, transmitted through the respiratory route. It presents with fever, conjunctivitis, runny nose, cough and Koplik spots in the mouth. Later on a rash develops from the face and upper neck spreading progressively throughout the body. ${ }^{1,2}$ Measles killed about 139,300 children in 2010 worldwide. ${ }^{3,4}$ According to unpublished data from the Littoral Regional Delegation of Public Health of Cameroon, 6 out of the 19 health districts reported measles outbreaks in 2011. There were over 371 cases and one death reported. About 163 (43.9\%) of the cases were from the Nylon Health District, an urban slum in the cosmopolitan city of Douala described in a previous paper. ${ }^{5}$ In view of measles elimination, one of the strategies defined by the Measles initiative collaborative group is an effective surveillance system to quickly recognize and respond to outbreaks. ${ }^{6}$

An Integrated epidemiological and laboratory-based surveillance is required to provide the necessary sensitivity and specificity to ensure that measles virus is detected. The World Health Organization (WHO) recommends that countries like Cameroon with elimination goals should monitor the quality of their surveillance systems by periodically calculating the performance level of core indicators. One of which applied to regional level, is to attain a reporting rate of $\geq 2$ discarded measles cases per 100,000 population per year in $\geq 80 \%$ of health districts. ${ }^{7}$

In order to meet its objectives, measles surveillance in Cameroon is case-based, nationwide and designed according to WHO norms. ${ }^{8,9}$ It is under the Expanded Programme on Immunization (EPI). Suspected measles cases that meet the case definition identified in the community or health facility are supposed to be reported to the District Service the same day. Blood specimen is collected from the patient and transmitted to the reference laboratory in the capital city, Yaoundé, through the Centre for Specimen Collection.

The littoral region is the $3^{\text {rd }}$ most populated of the ten regions of the country and serves as a corner stone for all health programs. Measles surveillance and routine vaccination activities have been ongoing since the reorganization of the EPI in Cameroon in 2002.The region registered its best EPI performance both in routine and surveillance activities in 2010 due to the development and implementation of certain novel strategies with the direct financial assistance from WHO and UNICEF. Unfortunately since then that performance has not been reiterated. We hereby describe the performance of the case-based measles surveillance of the littoral region in 2010 by person, place and time as well as determine delays in the system. Such a detailed analysis is expected to be adopted by the regional team for regular monitoring and feedback to districts to stimulate and maintain excellence. Most of the practices that contributed to the good performance may have to be brought in again.

\section{Materials and Methods}

\section{Setting}

In 2010, the population of the littoral region
Correspondence: Gerald Etapelong Sume, Delegation of Public Health, Littoral Region, Douala, P.O. Box 106, Cameroon.

Tel: +237.74.18.01.11 - +237.94.23.82.04.

E-mail: sumegerald@gmail.com; pampampascal@yahoo.com

Key words: measles, littoral region, delays.

Acknowledgements: to all the partners of the Central African Field Epidemiology and Laboratory Training Programme (CAFELTP): Bill and Melinda Gates Foundation, Centers for Disease Control and Prevention, CDC Foundation, African Field Epidemiology Network, World Health Organization, the Ministries of Public Health and the Ministry of Higher Education of Cameroon for the opportunity given us to be part of the program. Sincere gratitude to the staff of the Central Technical Group of the Expanded Programme on Immunization and the those of the Littoral Regional Unit of the EPI.

Contributions: all the authors' participated in drafting the study and the production of the proposals. Marie Kobela and Irène Emah provided completed and cleaned data. Gerald Etapelong Sume, Ditu Kazambu and Dieula Delisaint did and validated the analysis. All the authors participated in the write up, reading and validation of the article.

Conflict of interests: the authors declare no potential conflict of interests.

Received for publication: 23 March 2013.

Revision received: 7 September 2013.

Accepted for publication: 29 January 2014.

This work is licensed under a Creative Commons Attribution NonCommercial 3.0 License (CC BYNC 3.0).

(C) Copyright G.E. Sume et al., 2014

Licensee PAGEPress, Italy

Journal of Public Health in Africa 2014; 5:334

doi:10.4081/jphia.2014.334

was estimated at 2,610,944 inhabitants over a surface area of $20,250 \mathrm{~km}^{2}$. Situated along the banks of the Atlantic Ocean, the region is bounded by four (South West, West, Centre and South regions) of the remaining nine regions of the country. The region has 163 health areas and 19 health districts: 06 urban districts found in the cosmopolitan city of Douala, the economic capital of the country, 03 semi urban districts and 10 rural districts. The region is served by a general and a central hospital, two regional hospitals, 26 district and assimilated hospitals, 129 health centers and medicalized centers as well as several private and confessional health facilities.

\section{Study population and design}

It was a retrospective cross sectional study 
in which all suspected measles cases from the Littoral region as per the WHO case definition, registered in the Epi Info database of the Central Technical Group of the EPI in 2010 were included.

\section{Case definition}

A suspected measles case was any person living in any of the 19 health districts of the Littoral region in 2010 who presented to any of the health facilities with a Rash and Fever plus at least one of the following symptoms: cough, coryza, conjunctivitis.

\section{Specimen collection and laboratory analysis}

Once a suspected measles case was identified in a health facility, $5 \mathrm{~mL}$ of blood was collected from the patient within 30 days after the onset of skin rash. Serum was obtained after decanting or centrifuging in a sterile tube labeled with the patient's identification and specimen collection date. The sera were transported to the specimen reception centre in Yaoundé then the Centre Pasteur du Cameroun (CPC). Reference laboratory using a vaccine carrier with two ice packs at a temperature of +4 to $+8^{\circ} \mathrm{C}$ alongside the patient's filled measles investigation form. The sera were tested for measles-specific Immunoglobulin and/or rubella-specific Immunoglobulin. The results were sent to the Central Technical Group for the EPI which in turn sent feedback to the regions.

\section{Time intervals}

A health facility was expected to inform the district service within $24 \mathrm{~h}$ after receiving a suspected measles case. Once $5 \mathrm{~mL}$ blood sample was collected from a patient, the district service is supposed to ensure that the sample gets to the specimen reception centre in Yaoundé within $72 \mathrm{~h}$ who in turn transmits the sample to the CPC reference laboratory within $24 \mathrm{~h}$ after reception. The feedback is supposed to be transmitted to the Central Technical Group of the EPI by the CPC laboratory within 7 days. The Central Technical Group of the EPI sends feedback to the regions, regions to the district and district to health facilities.

\section{Data collection}

We extracted measles surveillance data of the Littoral region from the 2010 Epi Info database of the Central Technical Group of the EPI. All registered suspected cases were included in the analysis.

\section{Definition of outcome variables}

Some main outcome variables in the study were: i) measles vaccination status: whether the suspected measles case was vaccinated for measles as stated in the database and measured using a dichotomous scale (Yes or No); ii) patient delay: proportion of suspected measles cases that presented at a health facility more than $48 \mathrm{~h}$ after the onset of signs and symptoms expressed as a percentage; iii) health facility delay: proportion of suspected measles cases reported to the district service more than $24 \mathrm{~h}$ after they were seen at the health facility; iv) district service delay: proportion of blood specimen transmitted to the specimen reception centre more than 03 days after collection; v) specimen reception centre delay: proportion of blood specimen transmitted to the CPC laboratory more than $24 \mathrm{~h}$ after reception by the specimen reception centre in Yaoundé; vi) CPC laboratory delay: proportion of blood specimen results transmitted to the Central Technical Group of the EPI by the CPC reference laboratory after seven days of receipt of specimen.

\section{Data analysis}

Data was cleaned and analyzed using Epi Info 3.5.3 and Excel for Windows. Descriptive statistics were performed in terms of person (gender and age group), place (health districts), time (month of investigation), clinical characteristics and laboratory results of suspected measles cases as well as delays in various procedures as per the measles surveillance system. Proportions were calculated and the results presented using frequency tables and bar charts. The Chi-square test (and Fisher exact test using Winpepi version 11.8 where appropriate) was used to determine whether there is an association between gender, age group and measles vaccination status. A difference was considered significant if $\mathrm{P}<0.05$.

\section{Ethical consideration}

We received a written authorization from the Permanent Secretary of the EPI in Cameroon to extract and use data on measles surveillance in the littoral region for this work.
Extracted data was kept confidential and locked in a cabinet file and assessed only by the investigators.

\section{Results}

A total of 130 suspected measles cases were investigated by the health districts of the littoral region in 2010 .

\section{Description of suspected measles cases by person, time and place}

of the 130 suspected measles cases, 83 (64\%) were males and approximately 99 (76\%) of the cases were less than or equal to five years old. The age of suspected measles cases ranged from 2 to 372 months (31 years) with a mean age of $54.2 \pm 73.3$ months. Approximately $50 \%$ of the suspected cases were below 2 years. Males (35.5 \pm 45.8 months) were significantly younger $(\mathrm{P}=0001)$ than females $(87.3 \pm 97.9$ months).

In January 2010, 11 suspected measles cases were investigated in the littoral region. This dropped in February and stabilized around 15 cases from March to May same year before a peak of 23 cases was attained in June. Later the number of investigated measles cases dropped and remained low till the end of 2010 as illustrated in Figure 1.

Apart from Loum and Manoka health districts, all the remaining 17 health districts investigated at least one suspected measles case. Cité des Palmiers (23 cases), Nylon (19 cases) and Logbaba (16 cases) Health Districts investigated the highest number of suspected measles cases in 2010, in decreasing order. Four (21\%) health districts (Dibombari, Ngambe Yabassi and Pouma) investigated a case each; two (10.5\%) health districts (Nkongsamba and Edéa) investigated two

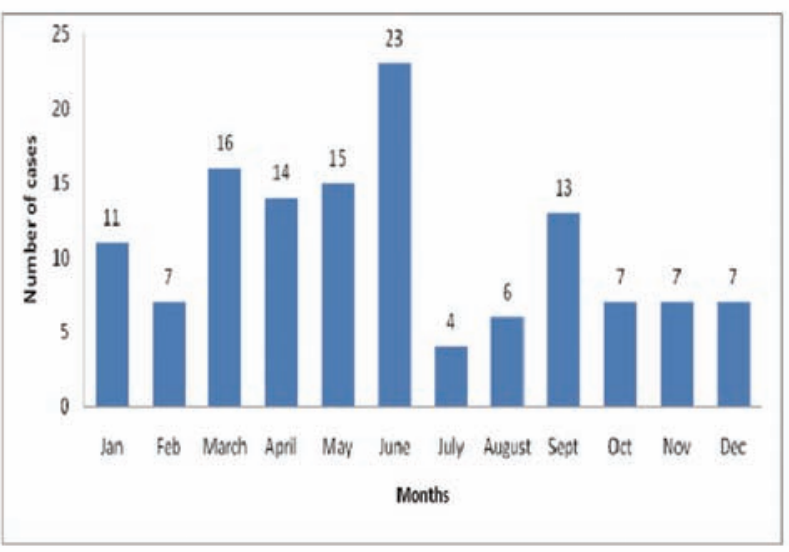

Figure 1. Distribution of suspected measles cases by months in 2010. 
cases each. Melong and Nkondjock, Mbanga and Ndom, Bonassama and Deido investigated three, four and fourteen cases respectively. The first six health districts in terms of number of investigated cases are the six urban health districts of the city of Douala.

\section{Clinical characteristics and labora- tory results of suspected measles cases}

Approximately, 64 (49\%) of the patients investigated for measles declared to have been vaccinated against measles amongst whom 56 (87.5\%) had received just a single dose in their lifetime. All of the suspected cases were alive during the investigation period. Only 6 (4.6\%) of the suspected measles cases were confirmed to have measles due to the presence of measles immunoglobulin $\mathrm{M}$ (IgM) in their serum. Rubella IgM were found in 10 (7.7\%) of suspected cases (Table 1).

Of the six measles IgM positive cases, 03 came from New Bell health district and one each from Cité des Palmiers, Deido and Manjo health districts. Of the ten rubella IgM positive cases, 4 and 2 came from Nylon and Cité des Palmiers respectively, while Bonassama, Deido, Logbaba and New Bell had one each. At least one positive case of measles and rubella (measles and rubella IgM positive cases) were identified in five (March, May, June, September and December) and seven (January, February, April, June, July, November and December) different months respectively out of the twelve months of 2010 . None of the months had more than two positive measles cases as seen in Figure 2.

Out of 130 suspected measles cases investigated, 6 were confirmed to be positive measles cases and 124 were discarded. This is approximately 2.4 times higher than the expected 52 discarded cases with respect to the total population of 2,610,944 inhabitants in 2010. Figure 3 shows that $15(78.9 \%)$ of the 19 districts went beyond the more than 2 discarded measles cases investigated per 100,000 population. Only four health districts (Manoka, Loum, Nkongsamba and Edéa) did not meet this target in 2010 with respect to their population.

Table 2 shows that there is a significant association $(\mathrm{P}=0.0048)$ between vaccination status and age group. The proportion of declared measles vaccination status in infants increases with age group, from $37.5 \%$ in less than 2 years, $59.3 \%$ in $2-5$ years and $66.7 \%$ in $6-10$ years. It then drops in the 11 and above to $15.4 \%$.

Delays in the measles surveillance system in the littoral region in 2010

About $50 \%$ of the suspected measles cases spent more than two days at home after the
Table 1. Some clinical characteristics and laboratory results of suspected measles cases in 2010.

\begin{tabular}{lcc} 
Variables & Categories & Number of cases (\%) \\
Vaccinated for measles & Yes & $64(49.2)$ \\
Number of measles & No & $66(50.8)$ \\
Vaccine doses received & 0 & $66(50.8)$ \\
Final Classification & 1 & $56(43)$ \\
& 2 & $7(05.4)$ \\
& Lab confirmed measles & $1(0.8)$ \\
Measles IgM lab status & Not lab confirmed & $6(04.6)$ \\
& Positive & $124(95.4)$ \\
Rubella IgM lab status & Negative & $6(04.6)$ \\
& Undetermined & $123(94.6)$ \\
& Positive & $1(0.8)$ \\
& Negative & $10(07.7)$ \\
& Undetermined & $112(86.1)$ \\
\hline Patient outcome & Not tested & $1(0.8)$ \\
& Pending & $6(04.6)$ \\
& Alive & $1(0.8)$ \\
\hline
\end{tabular}

IgM, immunoglobulin M; lab, laboratory.

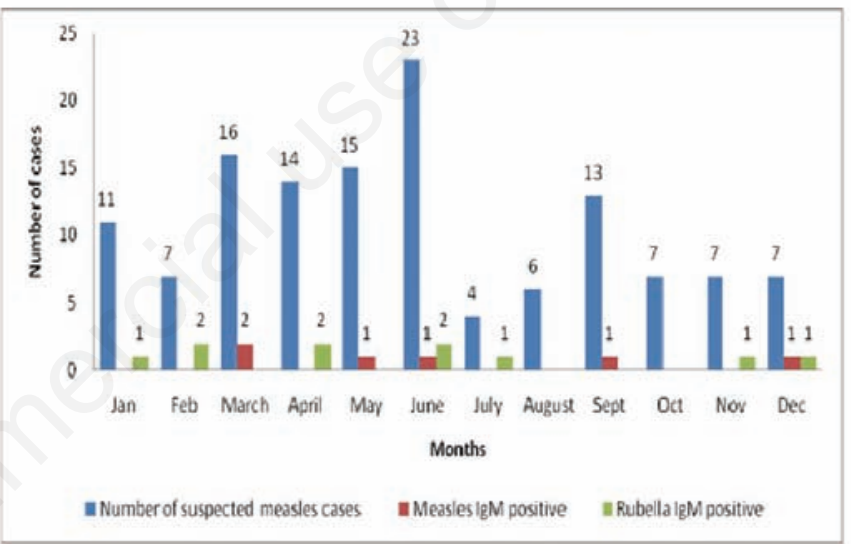

Figure 2. Number of suspected measles cases, measles immunoglobulin M (IgM)-positive and rubella IgM-positive over time in 2010.

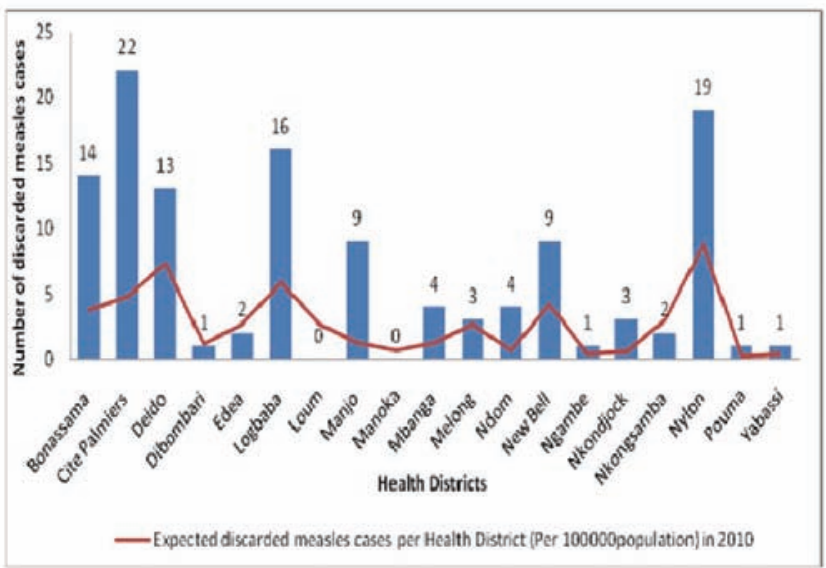

Figure 3. Number of discarded measles cases per health district with respect to specific targets in the littoral region in 2010. 
onset of symptoms before visiting a health facility. Likewise, half of the collected specimens were transmitted to the CPC reference laboratory more than $24 \mathrm{~h}$ after reception from the Specimen Collection Centre in Yaoundé. A quarter of health facilities informed the district service more than $24 \mathrm{~h}$ after they received the suspected case as shown in Table 3.

\section{Discussion}

Suspected measles cases were continuously investigated throughout 2010 by seventeen out of the nineteen health districts in the littoral region. Approximately $64 \%$ of the suspected cases were males and $76 \%$ were children under 5 . Only 6 out of the 130 investigated measles cases were confirmed as measles but not more than two for a given month. Almost half of the patients presented to the health facility $48 \mathrm{~h}$ after onset of symptoms and half of the specimen were transmitted to the laboratory by the centre for specimen reception more than $24 \mathrm{~h}$ after receipt. The region exceeded 2 discarded measles cases per 100,000 population and almost $90 \%$ of health districts investigated at least a measles case. The indicators for acute flaccid paralysis (AFP), yellow fever and neonatal tetanus surveillance just as that of measles were also met or improved in 2010 compared to previous years of thereafter.

Diseases under surveillance in the EPI program in Cameroon are poliomyelitis (AFP surveillance), yellow fever, neonatal tetanus and measles. The performance level of surveillance indicators for these diseases before 2010 in Cameroon in general and the Littoral region in particular were not optimal. The particularity of 2010 can be explained by the fact that, as early as the first trimester of 2010 , surveillance focal persons were identified per health facility and a regional capacity building workshop held on surveillance. The number of regional supervisors for surveillance in the regional level increased from two to eight. A networking was put in place between the health facility, district service and regional surveillance focal persons using a telephone directory. The region had access to a fixed phone line to call focal persons at lower levels at zero cost. A regional surveillance focal person made weekly calls to surveillance focal persons at lower levels who were not producing satisfactory results. Health facility surveillance focal persons had trimester meetings in each district to discuss challenges and update their knowledge. Regular monthly feedback was done from the region to lower levels. All this was made possible through regular financial support to all surveillance activities by WHO. This system collapsed by 2011 with irregular financial assistance, redeployment of trained personnel, non existence of the zero cost fixed phone, lack of interest from staff hence a drop or stagnation in the performance level of most indicators.

Manoka is one of the districts which did not investigate any case. In 2010, the district of Manoka which comprises 44 islands had severe accessibility problems due to the absence of a speedboat. The number of personnel in the district was limited to four staff and there was just a single functional health facili- ty in one of the islands. These challenges made the implementation of surveillance and other health programs difficult in Manoka. Presently, health programs are better implemented through outreach to the islands because the district has two speedboats, more than four staff in one functional health facility.

We cannot explain with certainty why a significant majority of the suspected cases were males. Approximately $90 \%$ of the suspected measles cases were children less than 11 years. Children do not only constitute a vulnerable group to many diseases but also rely on adults (parents and caregivers) to help them seek solutions to their health problems. Are the boys less tolerant to the clinical manifestations of measles, hence complaining and crying more which may lead to the parents seeking help for them easily or are they genetically more predisposed to exanthemas than the girls, is a question that still needs to be answered through further research.

The fact that $76 \%$ of suspected cases were under 5 children is explained by their vulnerability to contracting measles as well as other infections. ${ }^{2}$ The morbidity and mortality of the under 5 to measles is known to be very high than for the other age groups.,10,11 This applies for any exanthemas and explains why a lot of effort is usually used to address health

Table 2. Distribution of gender and age group by measles vaccination status of suspected cases in 2010.

\begin{tabular}{lcccc} 
Variables & Categories & \multicolumn{2}{c}{ Measles vaccination status } & P-value \\
& & Yes n (\%) & No n (\%) & \\
Gender & Males & $42(63.6)$ & $41(64.1)$ & 0.48 \\
& Females & $24(36.4)$ & $23(35.9)$ & \\
Age group (years) & $<2$ & $15(23.4)$ & $25(37.9)$ & $0.0048^{*}$ \\
& 2 to 5 & $35(54.7)$ & $24(36.4)$ & \\
& 6 to 10 & $12(18.8)$ & $6(09)$ & \\
& $\geq 11$ & $2(03.1)$ & $11(16.7)$ & \\
& & & &
\end{tabular}

*Fisher's exact test.

Table 3. Delays in the different procedures and stakeholders involved in measles surveillance in 2010 in the littoral region $\left(\mathrm{N}^{*}=130\right)$.

\begin{tabular}{|c|c|c|c|c|}
\hline Delays & Indicators & $\begin{array}{l}\text { Recommended } \\
\text { time limit (days) }\end{array}$ & Number $(\%)^{*}$ & Range (days) \\
\hline Patient delay & $\begin{array}{l}\text { Proportion of patients who went to a health facility } \\
\text { more than } 48 \mathrm{~h} \text { after the onset of signs and symptoms }\end{array}$ & 02 & $67(51.5)$ & $0-39$ \\
\hline Health facility delay & $\begin{array}{l}\text { Proportion of suspected measles cases notified } \\
\text { to the district service by health facilities more than } \\
24 \mathrm{~h} \text { after receiving the patient }\end{array}$ & 01 & $34(26.2)$ & $0-20$ \\
\hline District service delay & $\begin{array}{l}\text { Proportion of blood specimen transmitted to the central } \\
\text { level by district service } 72 \mathrm{~h} \text { post collection }\end{array}$ & 03 & $0(0.0)$ & $0-3$ \\
\hline $\begin{array}{l}\text { Specimen collection } \\
\text { centre delay }\end{array}$ & $\begin{array}{l}\text { Proportion of blood specimen collected by the specimen } \\
\text { collection centre in Yaoundé and transmitted to the } \\
\text { Centre Pasteur du Cameroun laboratory after } 24 \mathrm{~h}\end{array}$ & 01 & $65(50)$ & $0-5$ \\
\hline Laboratory delay & $\begin{array}{l}\text { Proportion of laboratory results sent to the CTG EPI } \\
\text { by the Centre Pasteur du Cameroun laboratory after } 7 \text { days }\end{array}$ & 07 & $0(0.0)$ & $0-7$ \\
\hline
\end{tabular}


issues such as vaccine preventable diseases in this age group.

The number of investigated measles cases follows a seasonal variation with the peak being attained during the raining season (March to September) and the trough during the dry season (October to February) except for the months of July and August where few cases were investigated while it was still raining. The raining season corresponds to cold weather and favors the transmission of flu and other respiratory tract infections. Thus irrespective of the causative agent, the incidence of viral infections (measles and rubella included) increases during the raining season.

Of the 66 (51\%) unvaccinated suspected measles cases, up to 49 (74\%) were under 5 children. This portrays a weak implementation of the reach every district vaccination strategy. The EPI program in Cameroon provides a series of vaccines free of charge to infants less than 12 months old and also present opportunities to catch up those aged less than five years who for one reason or the other did not complete their vaccination calendar. Thus everything being equal, we would expect just a few under 5 children not being vaccinated for measles.

Just a few of the investigated cases were confirmed to be measles and rubella infection. This is because of a sensitive case definition recommended by WHO that allows for any patient with rash and fever associated with at least one of cough, rhinitis and conjunctivitis to be considered a suspected case. ${ }^{8}$ Other pathologies with exanthemas as well could have been confirmed among the 130 suspected cases, but only rubella and measles were systematically tested. No measles outbreak was reported in 2010 because no health district had at least three confirmed measles cases (measles $\operatorname{IgM}$ positive) within a period of four weeks as defined in the EPI standard operating procedures. ${ }^{8}$ In 2009, there was a nationwide measles mass campaign targeting children aged 9 to 59 months. This must have helped to increase the number of under 5 children protected against measles hence reducing the number of measles susceptible infants.

There is a problem with the health seeking behavior of users of the health system. Measles is no longer a deadly infection because of improved nutrition status and decreased co-morbidities amongst the patients. There is the tendency of parents treating suspected measles cases at home with over the counter drugs or using traditional medicine. This further delays their ability to seek medical advice in qualified health institutions. Despite the fact that most health facilities and the district service are in the same town just as the Centre for Specimen Reception and the CPC laboratory, information and specimen transmission respectively were done late probably because of surveillance focal person dependence at health facility level and the need to collect and transmit several specimen at a time at the level of the Specimen Reception Centre.

The main limitation of this analysis is in the use of days instead of precise hours to estimate the delays. Normally, using dates as a proxy for hours does not give the precise time interval a specimen was received at the reception centre and when it was transmitted. We had to use the dates because the exact time was not mentioned in the forms. Also delays due to the transmission of results from the Central Technical Group of the EPI to the region, and region to the districts, were not calculated because the dates to be used for these calculations were not available in the database.

\section{Conclusions}

In 2010, the littoral region investigated 130 measles cases of which 6 were confirmed for measles and 10 for rubella. The region attained the $\geq 2$ discarded measles per 100,000 population target though two health districts did not investigate any measles case. More than half of the patients presented late at the health facility, a quarter of these health facilities did not inform the district service on time concerning the presence of a suspected case within their institution and approximately half of the specimens were transmitted by the centre for specimen reception to the laboratory late. Similar and regular data analyses have to be done by the regional EPI team and feedback given to the districts to carry out the necessary amendments. Hospital directors and the staff of the Centre for Specimen Reception have to be instructed to respect the time interval to inform the district service once a case is identified and to transmit specimen to the laboratory respectively. Health education sessions aimed at improving the health seeking behavior of users have to be planned and executed at all institutions in the region. Above all, some of the strategies that yielded fruit in 2010 have to be revisited.

\section{References}

1. Heymann DL. Control of communicable diseases manual. $19^{\text {th }}$ ed. Washington, DC: American Public Health Association Press; 2008. pp 402-8.

2. World Health Organization. Health topics. Measles. Available from: http://www. who.int/topics/measles/en/ Accessed: 4 Jan 2011.

3. World Health Organization. Programmes and projects. Immunization surveillance, assessment and monitoring. Measles; 2012. Available from: http://www.who. int/immunization_monitoring/diseases/m easles/en/ Accessed: 4 Dec 2012.

4. World Health Organization. Global measles and rubella strategic plan 20122020. Available from: http:// whqlibdoc. who.int/publications/2012/9789241503396 _eng.pdf Accessed: 4 Dec 2012.

5. Sume GE, Fouda AA, Kobela M, et al. Epidemiology and clinical characteristics of the measles outbreak in the Nylon Health District, Douala Cameroon: a retrospective descriptive cross-sectional study. Pan Afr Med J 2012;13:66.

6. World Health Organization. Media centre. Measles. 2009. Available From: http://www. who.int/mediacentre/factsheets/fs286/en/ Accessed: 5 Jan 2011.

7. [No authors listed]. Monitoring progress towards measles elimination. Wkly Epidemiol Rec 2010;85:490-4.

8. Ministère de la Santé Publique du Cameroun. Programme elargi de vaccination. Normes et standards du programme elargi de vaccination. $2^{\text {nd }}$ ed. Yaoundé: Ministère de la Santé Publique du Cameroun; 2009.

9. World Health Organization Regional Office for Africa. Guidelines for measles Surveillance; 2004. Available from: http://www.afro.who.int/index.php?option =com_docman\&task=doc_download\&gid =3675 Accessed: 15 Dec 2012 .

10. Wiysonge SC, Mawo NJ, Ticha MJ, et al. Migration and measles. Int $\mathrm{J}$ Epidemiol 2005;34:1443-4.

11. World Health Organization. Immunization against diseases of public health importance; 2005. Fact Sheet WHO/288. Available from: http://whqlibdoc.who. int/fact_sheet/2005/FS_288.pdf Accessed: 6 Jan 2011. 